\title{
Mujer y tradición clásica en los Ex Elegiis Tibulli, Propertii et Ouidii Selecti Versus (1504) de J. Murmelio
}

Gregorio Rodríguez Herrera (University of Las Palmas de Gran Canaria)

\section{Woman and Classical Tradition in I. Murmellius' Ex Elegiis Tibulli, Propertii et Ouidii Selecti Versus (1504)}

\begin{abstract}
In this paper we analyse the fragments dealing with women in I. Murmellius' Ex Elegiis Tibulli, Propertii et Ouidii Selecti Versus (1504), concluding that they reproduce a behaviour patterns of Renaissance society; most of the sentences and examples located describe women as fickle, licentious and deceitful. Besides, we show how female stereotypes are used to criticize behaviours unfit for men. Finally, this work also reveals that the Proyecto excerpta throws reliable data to carry out significant research on the influence of florilegia that could be extrapolated to other researches.
\end{abstract}

Keywords

florilegia; Latin elegy; Murmellius; gender; classical tradition; digital humanities 


\section{Los poetas elegiacos y los florilegios}

Actualmente parece superada la etapa inicial en la que los florilegios fueron estudiados casi exclusivamente con el fin de reforzar u obtener nuevas aportaciones en el campo de la crítica textual y edición de los textos de los autores clásicos, entre ellos los poetas elegiacos (Damon 1953; Ullman 1932). Así, de un lado, el estudio de los propios extractos y sus autores y, de otro, la concepción del florilegio como una obra nueva (Aldama Roy \& Muñoz Jiménez 2005; Fernández de la Cuesta 2008: pp. 28-32; Muñoz Jiménez 2004: pp. 273-274; Id. 2004' : pp. 123-133), han situado estas compilaciones también en el ámbito de la Tradición Clásica. Aun así, no es menos cierto que los florilegios se estudian generalmente en sí mismos, esto es: génesis, categorización, autores, transmisión y edición (Fernández de la Cuesta 2008; Muñoz Jiménez 2008). Hasta el momento, pues, son muy escasos los trabajos que realmente vinculen estas compilaciones de los autores clásicos y entre ellos los elegiacos latinos con la concepción ideológica de la sociedad que los genera (Codoñer 2002: p. 120) o que hayan puesto en relación la presencia de un autor clásico en un texto neolatino o vernáculo del Renacimiento con los excerpta de un florilegio. En definitiva, de un lado, se sigue tratando el florilegio como una obra con una función eminentemente escolar (Hankins 1998; Moss 1996) y, de otro, las compilaciones y estudios sobre la Tradición clásica de los elegiacos se centran en su influencia en las producciones neolatinas de carácter elegiaco o en las literaturas vernáculas del renacimiento (Gavinelli 2006; Parker 2012).

A todo esto contribuye el hecho de que estos estudios sobre la influencia de los florilegios se han realizado hasta ahora con una metodología filológica tradicional, ${ }^{1}$ es decir: lectura directa de los textos en soporte manuscrito o edición renacentista y transcripción de los fragmentos necesarios para justificar el análisis o el resultado de la investigación, entre ellos los dedicados a los elegiacos latinos (Fernández Cuesta 2009; Id. 2010; Id. 2012; Id. 2014; Rodríguez Herrera 2009; Id. 2010; Id. 2014; Id. 2015; Id. 2016; Villaroel Fernández 2009-2010; Id. 2015). Así pues, los florilegios son abordados parcialmente y con un método pre-digital que impide obtener con rapidez resultados significativos y extrapolables al ámbito de los estudios culturales, la historia de la educación o del pensamiento.

\section{El papel de la mujer en la elegía latina: la semilla de misoginia}

Desde el trabajo pionero de Lilja (1965) hasta el momento actual, la perspectiva de los estudios de género ha centrado en gran medida los estudios sobre la mujer en la elegía amorosa romana. Estos estudios la presentan en un papel reivindicativo, en tanto que mujer liberada de los roles tradicionales (Hallett 1973), como un falso reflejo de libertad, en tanto que está controlada por un narrador masculino (Greene 2012: pp. 359-362, James 2003, Wyke 2002), o como una excusa para explorar nuevos modelos de masculi-

1 Por el momento solo los proyectos de Nighman (2002; Id. 2011) ofrecen una acción sistemática para superar esta barrera. <www.chrisnighman.com/research-projects> (consulta 30.06.2017). 
nidad (Greene 2000; 2012: pp. 362-369). A ello hay que añadir estudios generales sobre la mujer en la Roma antigua, que en muchos casos utilizan los textos elegiacos para ejemplificar diferentes estereotipos femeninos (Cantarella 1991; Id. 1996; Pomeroy 1987).

Coinciden la mayoría de los trabajos en presentar a la mujer bajo un estereotipo muy particular que, de hecho, es signo distintivo de este género poético: la puella docta. Este estereotipo ofrece en sí mismo una descripción de la mujer que entra en conflicto con la moral y la educación de las romanas de clases alta (Hemelrijk 1999: pp. 79-81). La puella docta es una mujer seductora, sugerente, liberada y culta, que sabe de música y literatura, que baila, actúa y hace crítica del arte; mujeres con la condición de libertas o cortesanas que los elegiacos describen hermosas y apasionadas, pero también fuertes y dominantes; mujeres que, además, los poetas presentan dispuestas a renunciar a todo esto por ellos, aunque finalmente casi nunca sea así, ya que son ellas quienes dominan la situación (Cano Alonso 1998: p. 103; Luck 1974: p. 27).

Pero estas amadas no se perfilan en sus versos de manera positiva ya que también son codiciosas, volubles, infieles y dominantes. Así pues, realmente lo que relatan los poetas es que la puella docta está en una cierta posición de superioridad sobre el hombre al que dominan por completo y aunque su posición aparente es la de la clase alta sus actitudes la sitúan más cerca de la cortesana que de la matrona (James 2003: pp. 21-25 y 36-41). Realmente, como ya apuntase Hallett (1973: pp. 111-112), hay en la actitud de la puella elegiaca también una cierta misandria. Por otro lado, los poetas en tanto que amantes y también protagonistas de la obra literaria se enfrentan a la puella desde la fascinación y el deseo inicial hasta a la hostilidad y el sufrimiento final, de manera que desde su perspectiva androcéntrica realmente ofrecen una visión negativa de la mujer ya en el propio mundo romano. No es pues de extrañar que durante la Edad Media y el Renacimiento el cristianismo utilice estos textos con una intención moralizante para realzar o ejemplificar los uitia feminina (Rodríguez Domínguez \& Orgaz Baz 1991: p. 143), de manera que los elegiacos latinos, despojados, en cierta medida, de su auténtica voz o leídos sesgadamente (López Cayetano \& Rodríguez Herrera 2000; García de Paso \& Rodríguez Herrera 2005; Rodríguez Herrera 2009), contribuyan a desarrollar y apuntalar esta concepción misógina de la sociedad² (Bosch \& Ferrer \& Gili 1999; Labarge 1989; Rodríguez Domínguez \& Orgaz Baz 1991).

\section{La consideración de la mujer en los Selecti Versus de J. Murmelio}

Los Ex Elegiis Tibulli, Propertii et Ouidii ... Selecti Versus (Breda, 1504) de J. Murmelio ${ }^{3}$ son un florilegio de autores clásicos por secciones de autor en el que los excerpta siguen el

2 En cualquier caso no podemos olvidar, aunque no sea el objeto de este trabajo, que también hay un importante movimiento en el medievo y el Renacimiento de alabanza de las mujeres. Entre ellos cabe destacar la denominada "querelle des femmes" (Archer 2001; Claude 2000).

3 Juan Murmelio (1480-1517), humanista y pedagogo, fue rector en Münster (Westfalia) y en Alkmaar (Holanda) y comentarista de Persio y Juvenal, aunque fueron sus comentarios al De consolatione philosophiae de Boecio los que le dieron mayor proyección. También es autor de pequeños manuales como Scholasticorum 
orden que ocupan en el texto original. Además, J. Murmelio los vincula a un lema o titulus. El florilegio cuenta con 281 extractos de los que 24 son de Tibulo, 25 de Propercio y 232 de Ovidio, distribuidos de la siguiente manera: 34 Am., 59 Ars, 17 Epist., 16 Fast., 46 Pont., 27 Rem., 32 Trist. y 1 de la Consolatio ad Liuiam. Este florilegio es el primero específicamente de poetas elegiacos que se publica en el siglo XVI y, junto con el de D. Nano Mirabelio (1503), fue de los primeros florilegios temáticos que se publicaron en este mismo siglo. Su difusión especialmente en el ámbito alemán fue muy notoria, pues además de las dos ediciones que utilizamos en este trabajo hemos localizado otras veintiuna ediciones que abarcan casi dos siglos, desde la de Breda de 1504 a la de Heidelberg de 1681. Este importante número de reimpresiones demuestra que el florilegio circuló por Europa central, especialmente a partir de la década de los treinta del siglo XVI que es cuando se dispara la redición del texto. ${ }^{4}$ Además, la reputación de J. Murmelio como pedagogo en los círculos humanistas de su época debió contribuir a que esta obra, tuviese una gran acogida. El florilegio de Murmelio, además, se alinea con sus propias obras pedagógicas que se caracterizan por la brevedad, la simplicidad y la claridad, puesto que frente a la Polyanthea de D. Nano Mirabelio, la suya es una compilación breve, en la que prima el pragmatismo docente. Un ejemplo de ello son los lemas que precedan a los extractos en los que el humanista realiza en mucho casos un accesus ad excerptam, una explicación, más que un simple titulus.

El estudio que aquí presentamos ha obtenido los datos utilizando la versión beta del motor de búsqueda del Proyecto excerpta <http://tip.iatext.ulpgc.es/Excerptasearch/>, una herramienta que va a ofrecer acceso digital online de manera sencilla a florilegios poéticos latinos del siglo XVI que han sido etiquetados para la investigación comparada y por segmentos. Así pues, este estudio tiene también entre sus objetivos contribuir a validad la eficacia del Proyecto excerpta y mostrar su capacidad para abordar otros trabajos sobre estereotipos sociales reflejados en los florilegios, su relación con las producciones literarias o su influencia en la educación (Rodríguez Herrera \& Rodríguez Rodríguez \& Santana Jaria 2018).

\section{a) El corpus de extractos}

El buscador online del Proyecto excerpta nos ofrece los siguientes datos previos. En el florilegio de J. Murmelio la mujer ${ }^{5}$ es denominada de manera genérica con los términos femina (4) y puella (3), este último con el significado de 'amada', mientras que en el ámbito de sus actividades se la identifica como mater (1), meretrix (3) y lena (1) y uxor (3) aunque una de ellas a partir de su aparición en el lema del extracto. A estos hay que aña-

Enchiridion (1505), una obra en la que resalta la importancia de la buena formación y diseña un programa de enseñanza obligatoria para los estudiantes, y Pappa puerorum (1514), que fue muy conocido y utilizado en los primeros niveles de enseñanza del latín en Alemania, suiza y Holanda, del que se llegaron a distribuir 30.000 copias (Knape \& Kocher 1997; Leijenhorst 1986).

4 Un listado de todas estas ediciones puede consultarse en https://www.deutsche-digitale-bibliothek.de/ entity/100223354 (consulta 17.10.2017).

5 Para estudios concretos sobre la consideración de la mujer dentro obras del subgénero misceláneo incluido en el género didáctico-ensayístico puede consultarse Rodríguez Domínguez \& Orgaz Baz (1991: pp. 150-155); García de Paso Carrasco \& Rodríguez Herrera (2005); Nighman (2014). 
dir el término effeminatus (1) en la medida en que implica, como veremos, una crítica a la condición femenina. De estos términos vinculados a la mujer que recoge Murmelio seis se anuncian ya en los títulos o lemas bajo los que se encuadra cada extracto. El corpus, formado por catorce extractos y que hemos enumerado para su rápida identificación según su orden de aparición en el propio florilegio, es el siguiente: ${ }^{6}$

1. - Furor bellorum pessimus est, meliusque est domi pauperem uiuere, quam bellando cruentas opes quaerit.

TIBVLL. 1,10,33-42.

Quis furor est atram bellis accersere mortem?

Inminet, et tacito clam uenit illa pede.

Non seges est infra, non uinea culta, sed audax

Cerberus et Stygiae nauita puppis aquae.

Illic percussisque genis ustoque capillo

Errat ad obscuros pallida turba lacus.

Quam potius laudandus hic est, quem prole parata

Occupat in paua pigra senecta casa.

Ipse suas sectatur oues, at filius agnos,

Et calidam fesso comparat uxor aquam.

2. - Pacis Praeconia.

TIBVLL. 1,10,45-52.

Interea pax arua colat, pax candida primum,

Duxit araturos sub iuga curva boues,

Pax aluit uites et succos condidit uuae,

Funderet ut nato testa paterna merum.

Pace bidens uomerque uitent, at tristia duri

Militis in tenebris occupat arma situs,

Rusticus e lucoque uehit male sobrius ipso

Vxorem plaustro progeniemque domum.

3. - Foeminae sunt inconstantes.

TIBVLL. 3,4,61-62.

Ah crudele genus, nec fidum foemina nomen,

Ah pereat, didicit fallere si qua uirum.

4. - Foeminae sunt fallaces variae et mutabiles.

PROP. 2,9,31-32.

Sed uobis facile est uerba et componere fraudes,

Hoc unum didicit foemina semper opus.

6 En la edición transcribimos en primer lugar el lema, seguido de la referencia al autor y la obra según los criterios del TLL, y, a continuación el extracto para el que hemos seguido los criterios expuestos por Muñoz Jiménez (2004), a excepción de u/i semiconsonantes, para así respetar el estadio de la lengua en la compilación. 
Non sic incerto mutantur flamine Syrtes,

$\mathrm{Nec}$ folia hyberno tam tremefacta noto,

Quam cito foeminea non constat foedus in ira,

Siue ea causa gravis, siue ea causa leuis.

5. - In deceptores puellarum.

OV. Epist. 2,63-64.

Fallere credentem non est operosa puellam.

6. - In levitatem nimii cultus.

OV. Epist. 4,74-75.

Sint procul a nobis iuvenes, ut foemina compti:

Fine coli modico forma uirilis amat.

7. - De pöetarum inmortalitate et laude carminum.

OV. Am. 1,15,9-36. ${ }^{7}$

Dum fallax seruus, durus pater, improba laena

Vixerit, et meretrix blanda, Menandros erit.

8. - In puellis non est fides.

OV. Am. 2,16,45-46.

Verba puellarum, foliis leuiora caducis,

Irritaque ut uisum est, uentus et aura ferunt.

9. - Contra nimiam seueritatem in custodienda uxore.

OV. Am. 3,4,9-10.

Cui peccare licet, peccat minus, ipsa potestas

Semina nequitiae languidiora facit.

10. - In eos qui se peccasse gloriose praedicant.

OV. Am. 3,14,7-10.

Quis furor est quae nocte latent in luce fateri,

Et quae clam facias facta referre palam?

Ignoto meretrix corpus iunctura Quiriti,

Opposita populum submouet ante sera.

11. - Tempore oportuno consolatio et medicina est adhibenda.

OV. Rem. 127-134.

Quis matrem, nisi mentis inops in funere nati

7 Este extracto reproduce la conocida enumeración ovidiana de poetas griegos y romanos célebres. Solo reproducimos los versos $17-18$. 
Flere uetat? non hoc illa monenda loco est.

Cum dederit lachrymas, animumque impleuerit aegrum,

Ille dolor uerbis emoderandus erit.

Temporis medicina ualet, data tempore prosunt,

Et data non apto tempore uina nocent.

12. - Fletus foeminarum fallax.

OV. Rem. 689-690.

Neue puellarum lacrymis moueare caueto,

Vt flerent oculos erudiere suos.

13. - Choreae reddunt animum effoeminatum.

OV. Rem. 753-754.

Eneruant animos cytharae cantusque lyraeque

Et uox et numeris brachia mota suis.

14. - De falsa uulgi amicitia.

OV. Pont. 2,3,7-20.

Turpe quidem dictu, sed si modo uera fatemur, uulgus amicitias utilitate probat.

Cura quid expediat prius est quam quid sit honestum, et cum fortuna statque caditque fides.

Nec facile inuenias multis in milibus unum, uirtutem pretium qui putet esse sui.

Ipse decor recti, facti si praemia desint, non mouet et gratis paenitet esse probum.

Nil nisi quod prodest carum est, en detrahe menti spem fructus auidae, nemo petendus erit.

At reditus iam quisque suos amat et sibi quid sit utile, sollicitis subputat articulis.

Illud amicitiae quondam uenerabile nomen prostat, et in quaestu pro meretrice sedet.

\section{b) Análisis y estudio de los extractos}

En primer lugar, debemos destacar que en el florilegio de J. Murmelio no aparecen en ningún extracto los términos mulier, filia, coniux, regina, ornatrix o serua ${ }^{8}$ denominaciones que sí aparecen en las elegías latinas. Tampoco se recoge el término nutrix, aunque en los poetas elegiacos aparezca hasta veintitrés ocasiones y sea, en tanto que aliada de la puella enamorada, la actividad en la que alterna una visión positiva de protección de a la amada ${ }^{9}$ junto a otras en las que se la identifica con la lena.

8 La consulta realizada en The Electronic Manipulus florum <www.manipulusflorum.com> (consulta 30.06.2017) arroja 24 extractos para el término mulier, 4 para filia y 4 para serua.

9 Prop. 4,7,73-74; Ov. epist 18,97-117. 
Et soror et mater, nutrix quoque carpat amantem;

fit cito per multas praeda petita manus.

OV. Am. 1,8,91-92.

En segundo lugar hemos de establecer una doble tipología desde el punto de vista formal, de un lado sententiae y de otro lado exempla. En efecto, una serie de extractos presentan de manera concisa una máxima de carácter general con una cierta dimensión ética, ${ }^{10}$ por lo que sensu stricto, todo el extracto puede interpretarse como una sentencia. Otros, sin embargo, presentan un relato más amplio que refuerza el lema propuesto basándose en las circunstancias de un personaje o de una personificación. Estos extractos participan en cierta medida de la tradicional definición del exemplum en la retórica, ${ }^{11}$ pero al mismo tiempo incluyen una o varias sentencias normalmente al final del extracto en consonancia con la intención de la compilación. Consideramos sententiae los extractos 3, 5, 6, 8, 9, 12 y 13, y exempla, con sus correspondientes personajes o personificaciones los extractos 1 (La vida rústica como ejemplo de verdadera riqueza), 2 (El agricultor como ejemplo de la paz), 4 (La mujer como ejemplo de ser voluble y mentiroso), 7 (Menandro como ejemplos de comediógrafo), 10 (La prostituta como ejemplo de discreción), 11 (La madre como ejemplo del dolor) y 14 (La prostituta como ejemplo de la amistad que se vende).

En tercer lugar, desde el punto de vista del contenido podemos establecer tres grupos:

a) Extractos que denuncian vicios femeninos, entre los que están todos los que incluyen los términos genéricos femina y puella en el título o lema: no 3, 4, 7, 8, 11 y 12. Los excerpta 3, 4, 8 y 12 presentan los vicios a través de estereotipos femeninos habituales y presentes en la tradición misógina desde el mundo antiguo, esto es: la mujer voluble, la mujer mentirosa y la mujer infiel, pero muy focalizados hacia la denuncia del adulterio (Rodríguez Herrera 2004), que evidentemente es consecuencia de la acción de la mujer que es percibida en la sociedad medieval y renacentista como un ser imperfecto y un demonio que tienta constantemente al hombre (Anderson \& Zinsser 1991: pp. 38-46 y 73-75; Bosch \& Ferrer \& Gili 1999: pp. 10-22; Domínguez Rodríguez \& Rodríguez Álvarez 2004: pp. 52-55). Dentro de este listado de estereotipos femeninos negativos el extracto 11 es más sutil, pero igualmente crítico con la condición femenina. Efectivamente, el dístico final del exemplum, unos versos aparentemente piadosos que justifican que una madre beba vino, apto tempore, para aliviar el dolor por la muerte de su hijo, solo se entienden como limitación de uno de los estereotipos femeninos más criticados: la mujer ebria. ${ }^{12}$ Así pues, un verso piadoso, encierra realmente una crítica a la desmesura femenina. Estos estereotipos femeninos descritos por Murmelio a través de los elegiacos se complementan con el extracto 7 en el que presenta dos personajes

10 La sententia o gnômê es definida por Aristóteles (Rhet. 2,21, 1394a); Quintiliano (8,3,5); Hermógenes (2,7); Aftonio $(4,1)$ o Prisciano (2), así como por la Retórica a Herenio: Sententia est oratio sumpta de uita, quae aut quid sit aut quid esse oporteat in uita, breuiter ostendit (Rhet. Her. 24,4).

11 Para el exemplum nos fundamentamos en la definición de Cicerón: Exemplum est quod rem auctoritate aut casu alicuius hominis aut negotii confirmat aut infirmat (De inuent. 1,30,49).

12 Ya en la propia Roma es un tópico documentado que el vino hace perder a la mujer su pudicitia y empujarla al adulterio (Cantarella 1991: pp. 203-204; Id. 1996: pp. 84-85; Rodríguez Herrera 2004: pp. 43-44). 
vinculados a la puella elegiaca: la blanda prostituta en tanto que amada codiciosa (Navarro Antolín 1991) y la improba alcahueta, en tanto que cómplice de los adulterios (James 2003: pp. 52-68).

b) Extractos que realmente tienen al hombre como centro de la sentencia o el ejemplo, pero que utilizan conductas o estereotipos femeninos para criticar sus acciones: $\mathrm{n}^{\circ} 5,6,10,13$ y 14 . Así, por un lado, en los extractos 6 y 13 encontramos dos sentencias sobre el tópico del afeminamiento masculino como fuente de pecados y desvíos de la vida virtuosa. Uno centrado en el excesivo cuidado personal y otro en la mala influencia de la música y los bailes. Por otro lado, en los extractos 10 y 14, se nos ofrecen dos exempla en los que se sitúa al hombre por debajo de las prostitutas, la más vil de las mujeres. En el primero se arremete contra el hombre indiscreto que se vanagloria de sus conquistas y en el segundo contra el hombre que no honra la amistad por encima del interés. En ambos casos, la actitud del hombre es comparada con la de una prostituta. Por último, en el extracto 5 la sentencia critica una especie de donjuanismo sin escrúpulos, pero para ello recurre a un retrato de una puella ingenua, casi bobalicona, que, además, en el conjunto de la compilación es el único contrapunto al tipo dominante de la mujer voluble y mentirosa. Así pues, el mensaje de Murmelio parece ser que la mujer o de poco fiar o boba.

Estos extractos, en cierta medida, sacan a la luz otros modelos de masculinidad poco edificantes desde la perspectiva del compilador, pero para ello necesita recurrir a un paradigma negativo que una vez más es la mujer. Así pues, estos extractos, aun cuando el hombre es su protagonista, evidencian un tratamiento misógino de los elegiacos latinos.

c) Extractos sobre el matrimonio y la mujer como cónyuge: n 1 , 2 y 9. En los extractos 1, calidam fesso [marito] comparat uxor aquam, y 2, rusticus uehit uxorem domum, se presenta a la mujer en calidad de esposa sometida al marido. En estos extractos J. Murmelio evita situar los textos de los elegiacos bajo lemas que reflejen la visión medieval del matrimonio fundamentada en Pablo de Tarso (Corintios 7.1-11), según la cual el matrimonio es una concesión a aquellos que no pueden refrenar sus impulsos lujuriosos; por el contrario, se alinea con la visión renacentista en la que el matrimonio garantiza el bienestar de la sociedad a partir del designio natural que establece que la función del marido es obtener bienes y la de la mujer seguirlo obedientemente (Hankins 1998: pp. 168-169). Esta visión de la mujer subyugada por el marido se completa con otro extracto de J. Murmelio, ajeno al corpus de estudio, que trata el tema del matrimonio a partir de la habitual metáfora del yugo y los bueyes:

Coniugium inaequalium malum est.

OV. Epist. 9, 29-32

Quam male inaequales ueniunt ad aratra iuuenci,

Tam premitur magno coniuge nupta minor.

Non honor est, sed onus, species laesura ferentes,

Si qua uoles apte nubere, nube pari.

Este mismo extracto incide en que un matrimonio desigual es fuente de desgracias. Es digno de destacar que, aunque en el texto ovidiano es una mujer quien aconseja 
a otra mujer, Murmelio recuerda a sus receptores, los hombres que estudian latín, que este mensaje es también aplicable a ellos y que la mujer no debe estar por encima del hombre en línea con los textos de Pablo de Tarso (Timoteo 1.2.12 y Efesios 5.22), que tuvieron una profunda raigambre en la sociedad medieval y renacentista. ${ }^{13}$

Igualmente interesante es el tratamiento del cónyuge en el extracto 9, en el que se ofrece a los hombres un método para combatir la infidelidad de la esposa: no prohibirle nada. Aquí Murmelio le da claramente otra interpretación al pasaje ovidiano. Estos versos pertenecen a una elegía sobre el marido consentidor (Tracy 1976), un estereotipo frecuente en la elegía ovidiana (Rodríguez Herrera 2004: pp. 41-42), sin embargo, la descontextualización del extracto lo sitúa en otro tópico: "si quieres despertar la pasión por algo, prohíbela”. Esta nueva interpretación saca el fragmento ovidiano del ámbito masculino y lo sitúa en el de la mujer voluble y la esposa desobediente.

Estos extractos reflejan la visión negativa de la mujer que también aparece en los textos de los elegiacos, ya que recurren a uxor para ejemplificar los vicios de sus amadas. De hecho, en comparación, son pocos los extractos de estos autores clásicos en los que podríamos ofrecer la visión de la uxor romana: fiel, púdica y centrada en los intereses domésticos. $^{14}$

Por último y muy vinculado a los tres grupos que acabamos de señalar, debemos destacar que los tres poetas elegiacos están presentes en nuestro corpus de manera desigual. Los dos extractos de Tibulo se encuadran en el tercer grupo y nos presentan al poeta como defensor de las tradiciones romanas. Lejos queda de estos extractos Tibulo como poeta del amor hetero y homoerótico. Propercio aparece en una única ocasión y encuadrado en el grupo uno como azote de la mujer, sin que podamos advertir tampoco al poeta del amor y la muerte en sus extractos sobre la mujer. Finalmente, solo los de Ovidio pueden encuadrarse en los tres grupos y suyos son todos los extractos del grupo dos, en los que se presentan conductas masculinas criticables. Además, salvo el extracto 14 que pertenece a Pónticas, todos los demás pertenecen al género elegiaco.

Para reforzar este estudio sobre la consideración de la mujer en el florilegio de J. Murmelio, también hemos recopilado datos sobre los términos vinculados directamente al hombre utilizando la versión beta del motor de búsqueda del Proyecto excerpta <http:/ tip.iatext.ulpgc.es/Excerptasearch>. Estos datos han arrojado que, por ejemplo, solo el término homo ${ }^{15}$ (20) supera todas las denominaciones de la mujer en el florilegio; pero además hemos encontrado también los términos uir (1), puer (2), pater (2) y filius (1). Asimismo, frente a las connotaciones negativas de las "profesiones" femeninas que aparecen en los extractos de Murmelio, entre las masculinas se encuentran miles (5), nauta o nauita (4), agricola (3), rex (2), rusticus (2), arator (2) y pastor (1). Así pues, la visión androcéntrica del florilegio se intensifica si al análisis individualizado del binomio mujer frente hombre, le añadimos un análisis por comparación. No solo el número de

13 Los versículos son respectivamente: Docere autem mulierem non permitto, neque dominari in virum: sed esse in silentio y Mulieres viris suis subditae sint, sicut Domino.

14 Algunas de esas elegías o pasajes son Prop. 3,12; Ov. Epist. 1, 81-97; Ov. Epist. 7, 17-30; Ov. Ars 3, 7-24.

15 Aunque homo es el término que denomina a la especie, en estos textos resulta evidente que está polarizado como varón. 
términos relacionados con el hombre es mayor, sino que además no parecen tener connotaciones negativas o inmorales.

\section{Conclusión}

Del análisis de los extractos podemos concluir que J. Murmelio selecciona de los elegiacos latinos tanto sentencias como ejemplos a través de los que reproduce la visión androcéntrica de la sociedad renacentista acentuada por una concepción misógina de la mujer que es vista como un ser imperfecto y como una carga o una tentación para el hombre. Los uitia y los estereotipos negativos de la mujer que los elegiacos latinos reprodujeron en sus elegías mantienen su vigencia en la sociedad renacentista. El carácter voluble, licencioso y embustero de la mujer predomina en los extractos. De hecho, no encontramos textos positivos a excepción de los que tratan sobre el matrimonio, en los que, además, el compilador se alinea con el mundo antiguo, más que con la concepción medieval del matrimonio como alivio de la lujuria femenina. Es importante reseñar también que el compilador, en tanto que narrador masculino en esta obra nueva que son los Selecti Versus, se sirve de su concepción negativa de la mujer para criticar modelos de masculinidad poco edificantes. En otro orden de cosas, este trabajo también demuestra que el motor de búsqueda del Proyecto excerpta, actualmente en fase beta, realmente puede ofrecer datos fiables y con rapidez que permiten realizar investigaciones significativas y extrapolables sobre la influencia de los florilegios en aspectos concretos de la educación, de la estructuración del pensamiento europeo y de la tradición clásica.

\section{Bibliografía}

\section{Fuentes primarias}

Murmelio, J. (1504). Ex Elegiis Tibulli, Propertii et Ouidii ab Ioanne Murmellio Selecti uersus. Breda: Jacob de Breda. ${ }^{16}$

Murmelio, J. (1533). Ex Elegiis Tibulli, Propertii et Ouidii ab Ioanne Murmellio Selecti uersus. Parisiis: Christianus Wechelus.

\section{Fuentes secundarias}

Aldama Roy, A. Ma , \& Muñoz Jiménez, Mª J. (2005). Los florilegios. In B. Antón et al. (Eds.), Antiquae lectiones (pp. 217-223). Madrid: Cátedra.

Anderson, B. S., \& Zinsser, J. P. (1991). Historia de las mujeres. Una historia propia (Vol. I). Barcelona: Crítica.

16 Una copia digitalizada de esta edición puede consultarse en <http://digi.ub.uni-heidelberg.de/diglit/ murmellius1504> (consulta 17.10.2017). 
Archer, R. (2001). Misoginia y defensa de las mujeres. Antología de textos medievales. Madrid: Cátedra.

Bosch, E., Ferrer, V. A., \& Gili, M. (1999). Historia de la misoginia. Barcelona: Anthropos; Universitat de les Illes Balears.

Cano Alonso, P. L. (1998). Sobre los personajes de Propercio. Faventia, 20(2), 101-108.

Cantarella, E. (1991). La calamidad ambigua. Condición e imagen de la mujer en la antigüedad griega y romana. Madrid: Ediciones Clásicas.

Cantarella, E. (1996). Pasado próximo. Mujeres romanas de Tácita a Sulpicia. Madrid: Cátedra.

Claude, C. (2000). La querelle des femmes: la place des femmes des Francs à la Renaissance. Charlottesville: Le Temps des cerises.

Codoñer Merino, C. (2002). La educación hispánica en el siglo XVI. La compilación de Sententiae de André Rodrigues Eborense. Cataldo $\mathcal{E}$ André de Resende. Congresso Internacinal do Humanismo Português (pp. 111-121). Lisboa: Centro de Estudos Clássicos.

Damon, P. W. (1953). A Second Propertius Florilegium. Classical Philology, 48, 96-97.

Domínguez Rodríguez, Ma. V., \& Rodríguez Álvarez, A. (2004). Moral Considerations on Female Sexuality in Late Medieval English Scientific Treatises. In F. Alonso Almeida, \& A. Rodríguez Álvarez (Eds.), Voices on the Past. Studies in Old and Middle English Language and Literature (pp. 49-61). A Coruña: Netbiblo.

Fernández de la Cuesta, B. (2008). En la senda del Florilegium Gallicum. Edición y estudio del florilegio del manuscrito Córdoba, Archivo Capitular 150. Louvain-la-Neuve: Brepols.

Fernández de la Cuesta, B. (2009). Los Fastos de Ovidio en los Florilegios medievales. In J. F. González Castro (Ed.). Perfiles. Grecia y Roma. Actas del XII Congreso Español de Estudios Clásicos (pp. 217-223). Madrid: Ediciones Clásicas.

Fernández de la Cuesta, B. (2010). La singular lectura de los Fastos de Ovidio en el florilegio de Douai, Bibliothèque Municipale ms.79. Cuadernos de Filología Clásica. Estudios Latinos, 30, 101-116.

Fernández de la Cuesta, B. (2012). Los Fastos de Ovidio en el Florilegium Gallicum. Revue d'Histoire des Textes, 7, 221-250.

Fernández de la Cuesta, B. (2014). La selección de pasajes de Ovidio en el manuscrito 246 de la Biblioteca Histórica de Santa Cruz de Valladolid. In Ma ${ }^{\text {a }}$ T. Callejas Berdonés et al. (Eds.), Manipulus studiorum en recuerdo de la profesora Ana María Aldama Roy (pp. 367-374). Madrid: Escolar y Mayo.

García de Paso Carrasco, Ma . D., \& Rodríguez Herrera, G. (2005). La consideración de la mujer en marginalia a las Elegías de Propercio. Faventia, 27(1), 63-72.

Gavinelli, S. (2006). The Reception of Propertius in Late Antiquity and Neolatin and Renaissance Literature. In H.-C. Günther (Ed.), Brill's Companion to Propertius (pp. 399-416). Leiden - Boston: Brill.

Greene, E. (2000). Gender Identity and the Elegiac Hero. Arethusa, 33, 241-262.

Greene, E. (2012). Gender and Elegy. In B. K. Gold (Ed.), A Companion to Roman Love Elegy (pp. 357-371). West Sussex: Wiley-Blackwell.

Hallett, J. P. (1973). The Role of Women in Roman Elegy: Counter-Cultural Feminism. Arethusa, 6, 103-124.

Hankins, J. (1998). El humanismo y los orígenes del pensamiento político europeo. In J. Kraye (Ed.), Introducción al humanismo renacentista (pp. 159-187). Madrid: Cambridge University Press. 
Hemelrijk, E. A. (1999). Matrona docta. Educated Women in the Roman Élite from Cornelia to Julia Domna. London - New York: Routledge.

James, S. L. (2003). Learned Girls and Male Persuasion. Gender and Reading in Roman Love Elegy. Berkeley: University of California Press.

Knape, J., \& Kocher, U. (1997). Murmellius, Johannes. Neue Deutsche Biographie, 18, 613 (http:// www.deutsche-biographie.de/pnd100223354.html; consulta 06.03.2016).

Labarge, M. W. (1989). La mujer en la Edad Media (pp. 248-249). Madrid: Editorial Nerea.

Leijenhorst, C. G. van (1986). Johannes Murmellius. In P. G. Bietenholz, \& T. B. Deutscher (Eds.), Contemporaries of Erasmus. A Biographical Register of the Renaissance and Reformation (Vol. II; pp. $\left.470^{\mathrm{b}}-471^{\mathrm{a}}\right)$. Toronto - Buffalo - London: University of Toronto Press.

Lilja, S. (1965). The Roman Love Elegists' Attitude to Women. Helsinki: Suomalainen Tiedeakatemia.

López Cayetano, E. F., \& Rodríguez Herrera, G. (2000). Los motivos amatorios en los marginalia del Scorialensis S.III.22. Cuadernos de Filología Clásica. Estudios Latinos, 19, 141-156.

Luck, G. (1974). The Woman's Role in Latin Love Poetry. In G. Galinsky (Ed.), Perspectives of Roman Poetry (A Classics Symposium) (pp. 15-31). Austin: University of Texas Press.

Moss, A. (1996). Printed Commonplace-Books and the Structuring of Renaissance Thought. Oxford: Clarendon Press.

Muñoz Jiménez, Ma. J. (2004a). Proverbia Marcialis: lecturas parciales de Marcial en los florilegios medievales. In J. Iso et al. (Eds.), Hominem pagina nostra sapit: Marcial, 1900 años después (pp. 271-293). Zaragoza: Institución Fernando el Católico.

Muñoz Jiménez, Mª J. (2004b). La edición de florilegios como edición especial. Exemplaria clasica, 8, 123-133.

Muñoz Jiménez, Mª J. (2008). Un florilegio de biografías latinas. Edición y estudio del manuscrito 7085 de la Biblioteca Nacional de Madrid. Louvain-la-Neuve: Brepols.

Navarro Antolín, A. (1991). Amada codiciosa y Edad de Oro en los elegiacos latinos. Habis, 22, 207-221.

Nighman, Ch. L. (2002). The Electronic Manipulus florum Project (www.manipulusflorum.com). Medieval Sermon Studies, 46, 97-99.

Nighman, Ch. L. (2011). The Janus Intertextuality Search Engine: A Research Tool of (and for) the Electronic Manipulus florum Project, Digital Medievalist, 7 (http://www.digitalmedievalist.org/ journal/7/nighman/; consulta 05.03.2016).

Nighman, Ch. L. (2014). The Manipulus florum, Johannes Nider's Formicarius, and Late Medieval Misogyny in the Construction of Witches Prior to the Malleus Maleficarum. Journal of Medieval Latin, 24, 171-184.

Parker, H. N. (2012). Renaissance Latin Elegy. In B. K. Gold (Ed.), A Companion to Roman Love Elegy (pp. 476-490). West Sussex: Wiley-Blackwell.

Pomeroy, S. B. (1987). Diosas, rameras, esposas y esclavas. Mujeres en la antigüedad clásica. Madrid: Akal Universitaria.

Rodríguez Domínguez, S., \& Orgaz Baz, B. (1991). El tema de la mujer y la persistencia de la misoginia en la cultura humanista y renacentista españolas. Revista de Historia de la Psicología, 12, 143-156.

Rodríguez Herrera, G. (2004). Penelope uenit, abit Helene. Mujer y transgresión en la elegía y el epigrama latinos. In A. Mateo del Pino, \& G. Rodríguez Herrera (Eds.), Metáforas de perversidad. 
Percepción y representación de lo femenino en el ámbito artístico y literario (pp. 35-53). Santa Cruz de Tenerife: Fundación Mapfre Guanarteme.

Rodríguez Herrera, G. (2009). La selección de Propercio en los florilegios latinos de los siglos XIII al XVI. In Ma. D. García de Paso Carrasco, \& G. Rodríguez Herrera (Eds.), Selección, manipulación y uso metaliterario de los autores clásicos (pp. 99-123). Zaragoza: Libros Pórtico.

Rodríguez Herrera, G. (2010). Propercio en el Viridarium Illustrium Poetarum de Octaviano Mirándola: origen e influencias. Cuadernos de Filología Clásica. Estudios Latinos, 30(2), 295-320.

Rodríguez Herrera, G. (2014). Los excerpta de Tibulo en el florilegio de Cristóbal García Guillén de Paz (ms. 246 BH Santa Cruz, Valladolid). In Mª. T. Callejas Berdonés et al., Manipulus florum en recuerdo de la profesora Ana Aldama Roy (pp. 845-857). Madrid: Escolar y Mayo.

Rodríguez Herrera, G. (2015). Propercio en la Polyanthea de D. Nano Mirabelio. In J. Ma Maestre Maestre et al. (Eds.), Humanismo y pervivencia del mundo clásico. Homenaje al Profesor Juan Gil (Vol. 4.; pp. 1911-1924). Alcañiz - Madrid: IEH-CSIC.

Rodríguez Herrera, G. (2016). La selección de los elegiacos latinos en las Sententiae et Exemplum (1557) de André Rodrigues de Évora. Habis, 47, 275-290.

Rodríguez Herrera, G., Rodríguez Rodríguez, G., \& Santana Jaria, O. J. (2018). El estudio de los florilegios latinos del siglo XVI en la era digital: el Proyecto excerpta. In J. Ma Maestre Maestre et al. (Eds.), Humanismo y pervivencia del mundo clásico VI. Homenaje al profesor Eustaquio Sánchez Salor. Alcañiz - Madrid: IEH-CSIC (en prensa).

Tracy, V. A. (1976). The leno-maritus. Classical Journal, 72, 62-64.

Ullman, B. L. (1932). Tibullus in the Mediaeval florilegia. Classical Philology, 27,128-174.

Villaroel Fernández, I. (2009-2010). Tibulo en el manuscrito 94 de la Biblioteca Pública del Estado en Tarragona. Boletín de la Academia de Buenas Letras de Barcelona, 52, 97-118.

Villaroel Fernández, I. (2015). Ovidio en el ms. 94 de la Biblioteca Púbica del Estado en Tarragona. In J. Ma Maestre Maestre et al. (Eds.), Humanismo y pervivencia del mundo clásico. Homenaje al Profesor Juan Gil (Vol. 1; pp. 443-454). Alcañiz - Madrid: IEH-CSIC.

Wyke, M. (2002). The Roman Mistress. Oxford: Oxford University Press.

Dr. Gregorio Rodríguez Herrera / gregorio.rodriguez@ulpgc.es

Research Institute of Text Analysis and Applications

University of Las Palmas de Gran Canaria

Edificio de Humanidades "Millares Carlo"

c/ Pérez del Toro 1, 35003 Las Palmas de Gran Canaria, Spain 